\title{
Long Term Technical and Economic Evaluation of Hydrogen Storage Technologies for Energy Autarkic Residential Complexes
}

\author{
L. Schindhelm ${ }^{1} \quad$ A. Vojacek $^{2} \quad$ J. Brunnemann ${ }^{2}$ \\ ${ }^{1}$ Fraunhofer Institute for Chemical Technology, Pfinztal, Germany lucas.schindhelmeict. fraunhofer. de \\ ${ }^{2}$ XRG Simulation GmbH, Hamburg, Germany, \{vojacek, brunnemann\} $@ x r g-s i m u l a t i o n . d e$
}

\begin{abstract}
We present an assessment of different types of hydrogen storages used as long term energy buffers for a local community complex of households in terms of economics and energy autarky. The models used in this study are partly based on the TransiEnt Modelica Library, which is being developed for the dynamic simulation of coupled energy supply systems with high shares of renewable energies. It turns out that dynamic simulations are mandatory in order to optimise the system parameters. Starting from a best case evaluation of a one year linear optimisation we develop a forecast based control logic of the whole energy system, including its physicalities. Based on our results, a storage consisting of pressurized gas bottles has proven to be the most favourite solution in terms of price and level of autarky. A liquid organic hydrogen carrier might be a competitive alternative for larger urban districts.

Keywords: Energy system, autarky, economic, long term, Hydrogen storage, Control logic, TransiEnt library, ClaRa library, Linear optimisation
\end{abstract}

\section{Introduction}

\subsection{Context of this Project}

The German Renewable Energy Law (BMU 2021) aims for $80 \%$ of electrical and $60 \%$ of primary energy supply from renewable energy sources (RES). The energy density with respect to surface area is magnitudes smaller for RES than for centralized energy systems like nuclear power plants. Energy transmission lines would have to be scaled to the massive volatile peak power output of RES, especially photovoltaics (PV), in order to transport energy e.g. from one part of the country to the other. Decentralized energy systems can be an alternative to reduce the costs and organizational difficulties of building additional transmission capacity by various means of local energy storage and smart energy management.

Funded by the $6^{\text {th }}$ energy research program (BMU 2011) the joined research project "Energy Buffer" (EP) was carried out. In the course of this project a "hydrogen battery"(HB) comprising an PEM-electrolyser (ELY), a PEM-fuel cell (FC) (Proton Motor Fuel Cell GmbH 2021), an energy management (EMS) and a pressurized hydrogen storage (pressure level: 30 bar) was designed and a demonstrator build from market-available components. A modular design was applied to a passive house residential area in Stadtroda (Thuringia, Germany) (9 houses and one central facility) as the key reference point. The residential area is planned to be $99 \%$ time- and energy quantityautarkic (level of autarky $L o A_{\text {time }}=L o A_{\text {energy }}=0.99$ ). PV is the exclusive energy source. The heat supply is based on a detailed prescribed concept (Frey 2019) and the passive house standard (PHI 2021).

The process of developing the project EP started as early as 2011. Recent commercial designs with similar parameters can be found in (Stiftung Umwelt Arena Schweiz 2021) and (HPS Home Power Solutions GmbH 2021).

Technological and economic evaluations of hydrogen storages in energy supply systems have been carried out earlier, e.g. in (Macagno 2004). In Modelica, the modeling and simulation of hybrid renewable energy systems containing among others PV and storages have been investigated in (Fritzson 2013), numerical implications of such models have been analysed in (Kofman 2016). In a recent work (Bentvelsen 2019) investigated a controllable electrolyser using OpenModelica. There a wind turbine provides electric power which is scheduled by a forecast based control algorithm between an industrial local grid and an electrolyser. A Modelica model of a fuel cell and a metal hydride storage has been developed in (Scarisbrick 2019), focusing on physical aspects of the components. A hydrogen production system for residential buildings has been modelled and investigated in (Henriquez 2018). There again the focus was put on the component modelling, while the control algorithm is not presented in detail.

While in the cited literature individual system components models have been created for the particular simulation study the work presented in this paper is based on standard components of the TransiEnt library (TransiEnt v1.2.0 2020), which are extended by certain physicalities, such as load depending efficiencies, minimum loads or limits on yearly start/stop cycles. These properties are relevant for operating the system using an underlying control logic, which is based on a $24 \mathrm{~h}$ ahead weather and demand forecast model.

\subsection{Outline of Paper}

In subsection 2.1 the main results of a preliminary linear optimisation of the HB system are presented, which 
is based on certain idealisations of the real system. These results serve as an upper bound on the performance of the real system. The necessity of developing a dynamic model of HB in Modelica for a more extractable and realistic approach is developed in subsection 2.2. There we also elaborate on different available storage technologies and discuss pros and cons of two storage types that were finally analysed.

Used libraries and physicality-based models of system components that were newly developed in this work are shown in subsection 2.3. The steps of developing the crucial dynamic system logic and the effects of improving the logic regarding system performance in comparison to results from linear optimisation are presented in subsection 2.4. The control logic is then compared to the initial linear optimization (LO) results for a one year time period. We show that a $24 \mathrm{~h}$ ahead forecast model is sufficient in order to bring the real system close to the idealised LO result, if physicalities are neglected. In section 3 the analysed setups of HB are evaluated in terms of their autarky level and costs. An assessment of the feasibility of HB in the temporary economic state and policies can be found in section 4. Usability and ability of the developed Modelica libraries and models are depicted in section 4 as well to conclude this work.

\section{Preliminary Work}

\subsection{Linear Optimisation}

Firstly, a linear optimisation approach for modelling was taken to further guide the development of a more detailed physical model in Modelica, in particular, it provided results of an ideal case. The components of the $\mathrm{HB}$ and PV have been modelled for the optimisation in oemof (Hilpert et al. 2018). Oemof uses mixed-integer linear programming (MILP) to mathematically optimise the system for minimising the electrical energy import from the superior grid. Heat supply and its electricity demand are modelled and simulated in TRNSYS (University of Wisconsin-Madison Solar Energy Laboratory 1975), where transient physical models are utilised under use of a case-specific control logic. The electricity demand of the heat supply is used as input data for the oemof simulation, whereas the waste heat of ELY and FC are input data for the TRNSYS simulation. In this way there is an implicit serial coupling between both tools.

\subsubsection{Parameters of Physical Models and Input Data}

In Table 1 the main parameter sets, that are used in the optimisation, are shown. Further, there were considered additional technical constraints for ELY and FC such as maximum start-stop cycles per annum 500/1500 and maximum runtime 2000/4500 respectively. The electrical demand, excluding heat supply, is extracted from real data of sonnen $\mathrm{GmbH}$, processing nine individual houses' annual electrical consumption between 2-3 MWh/a. Note that ELY and FC units each consist of two independent modules in order to better cope with partial load. The optimisation time step is one hour.

Table 1. Characteristics of the system components.

\begin{tabular}{lccc}
\hline Device & Efficiency & Capacity & el. Power \\
\hline & $\%$ & $k W h$ & $k W$ \\
\hline FC & 47 & - & 4.7 \\
ELY & 51 & - & 5.8 \\
hydrogen & & 13422 & \\
storage & - & $(400 \mathrm{~kg})$ & - \\
lithium-ion & $93.3 / 91.6$ & & \\
batteries & (out/in) & 106 & 33.3 \\
PV & n.a. & - & 90 \\
heat pump & - & - & $9 \times 2.1$ \\
\hline
\end{tabular}

\subsubsection{Interpretation of Optimisation Results}

This section focuses on the optimisation results regarding capacity of the hydrogen storage, since the cost of the storage capacity is comparably high $(\sim 1000 €$ per $\mathrm{kg} \mathrm{H}_{2}$ ). Further, capacities and peak power values were determined within technical and regulatory limits. Reasonable engineering guesses and preliminary optimization were used (e.g. for number of FC modules etc.). The set of applicable devices was further limited to the product portfolio of the participating companies and by some budget restrictions. Hence, initial, quite rigid device choices had to be made, that are taken as granted in this study.

The optimisation results are in good agreement with the calculation of ideal Modelica model excluding physicalities (see Figure 6 in subsubsection 2.4.3) whose main outcome are presented in Table 3 and in Table 4.

Table 2. Level of autarky from LO in terms of energy and time.

\begin{tabular}{lll}
\hline Capacity of storage $[\mathrm{kg}]$ & LoA $A_{\text {energy }}$ & LoA $A_{\text {time }}$ \\
\hline 400 & 0.96 & 0.98 \\
300 & 0.92 & 0.94 \\
200 & 0.88 & 0.92 \\
\hline
\end{tabular}

It is clearly visible that the storage capacity of $400 \mathrm{~kg}$ hydrogen shows the best performance regarding autarky (see Table 2). The PV supply gap and the high energy demand of the heat pumps in the winter months lead to a rapid decline of the state-of-charge (SOC). As a consequence, high amounts of hydrogen have to be stored and it is crucial to maximize the stored hydrogen mass in summer. For this, decisions, like storing an energy surplus in the batteries for short-term or in the HB for the longterm, have to be made. It is of great importance to maximize the productivity of FC and ELY without overstretching the operational constraints. This overstretching could easily happen, if e.g. ELY is always switched on if minimal energy surplus sufficient for its operation is detected. 
ELY than could lose crucial hours of high productivity. In this optimisation study the solver has ex-ante knowledge of all input data sets, so the decision, e.g. when to run which module of ELY, is not reproducible in real conditions and extremely dependent on the highly specific input data. Since there is only a cost penalty for using the superior grid to cover the energy demand, each solver run can use the full range of a constraint limits and options, what may lead to inscrutable behaviour of the components. It is possible that one module is switched off for one hour and is then reactivated for the next hour, while the second module runs for the switched off hour. Another example of this artefact is the decision, when to start filling the tank. Especially, in the case of $200 \mathrm{~kg}$ hydrogen, it was observed that the systems only starts producing hydrogen later in the year. It is enough to fill the tank in this specific case, but dependencies of weather and real demand are not accounted for. Therefore, this behaviour is not desirable for the system while using a real process control and, consequently, not foreseeing the time profiles of demand, PV etc. on a one year time scope. To achieve this, a control system has to be implemented, that can manage short-term and long-term storage decisions.

In order to test and validate the optimisation results under real conditions, XRG Simulation $\mathrm{GmbH}$ received the task to develop such a process control logic and to simulate the system in Modelica using the same input data as processed in linear optimisation.

\subsection{Request for a Modelica System Model}

By using a dynamic Modelica System Model it is possible to implement the requested more dynamic and comprehensible (logic) model of the demonstrator. Following tasks and aspects are adressed in the Modelica System Model to add significant value to the results of the linear optimisation:

- implementing an extractable distribution logic of electric power depending on time and load (ELY-FCgrid-batteries)

- inclusion of on/off cycles of components and their physical constraints, i.e. start-up / shut down delays, minimum/maximum loads and battery capacity

- avoidance of faulty switching (artefact from linear optimization) on/off modules of ELY and FC

- analyzing of different $\mathrm{H}_{2}$-storage technologies, especially utilising improved physicalities

- optimisation of the system parameters and its control logic under real operation

Consequently, a Modelica model, was developed, which shall describe the energy system at a higher degree of physical precision, while still performing with efficient calculation time simulating one calendrical year.

\subsection{Component Model Library}

TransiEnt v1.2.0 (2020) Modelica library was chosen as starting point for modelling. It already includes a comprehensive collection of models to describe and analyse integrated energy systems with high share of renewable energies according to environmental and economic aspects. The library was developed in the research project TransiEnt.EE and its successor project ResiliEnt.EE (2021). The TransiEnt library uses the ClaRa v1.3.0 (2020) Modelica library which allows dynamic simulation of thermal hydraulic energy systems such as power plants, thermal storages etc. This library combination creates a comprehensive and powerful tool for modelling local energy systems and power plants. All supplement models developed within this project have been put together in a Modelica library. It consists of models of control logic, ELY, FC, storages, compressor, separator, cost models of key components and additionaly handy models such as sensors for measurement of power on ElectricPowerPort and calculation the cost to/from grid etc.

\section{Selection of applicable $\mathrm{H}_{2}$-storage technologies.}

In order to select applicable storage technologies to be modelled an extensive literature study (HydrogenEurope 2020; Hydrogenious 2020; FuelCellStore 2020) was performed. It evaluates the current state of the art of hydrogen storage technology for small scale residential areas. The study revealed two preferable storing techniques for hydrogen: pressurized and liquid organic carrier $\mathrm{LOHC}$. Pros ("+") and cons ("-") of these technologies are:

\section{Pressurized Storage System}

+ most common hydrogen storage technology

+ very simple release mechanism, minimal complexity at customer site

+ price relatively low

- heavy system due to pressurised components (steel pressure tanks/bottles)

- low storage density

- different pressure levels used for different applications

Within this paper we consider 28 bars tanks (approx. 2 $\mathrm{kg} / \mathrm{m}^{3}$ at $20^{\circ} \mathrm{C}$ ) and 200 bars bottles (approx. $14 \mathrm{~kg} / \mathrm{m}^{3}$ at $20^{\circ} \mathrm{C}$ ).

\section{Liquid Organic Hydrogen Carrier (LOHC)}

+ demonstrator units already built (Hydrogenious 2020) with parameters sufficient for this project.

$+\mathrm{H}_{2}$ stored at ambient condition (temperature, pressure), hardly inflammable, non-explosive

+ light weight system (i.e. storage in plastic canisters)

- lower overall efficiency (energy required for releasing $\mathrm{H}_{2}$ (approx. at $300^{\circ} \mathrm{C}$ ) from $\mathrm{LOHC}$, at times when there is no excess of $\mathrm{PV}$ power) 
Other approaches of storing the hydrogen are currently either too expensive, too complex for a small scale urban place, high energy demanding, technically immature or inquiring specific condition of the underground such as e.g. salt caverns, exhausted oil and gas fields etc. These storage systems are: Liquefied $\mathrm{H}_{2}$; Cold-and cryocompressed $\mathrm{H}_{2}$; Material-based $\mathrm{H}_{2}$ storage; Hydride storage systems; Surface storage systems and Underground storage. Consequently, these systems have not been further evaluated in this work.

Model of ELY \&FC\&Pressurized Storage. The model of ELY, $\mathrm{FC}$ and $\mathrm{H}_{2}$ pressurized storage was implemented as one lumped component in very simple manner. The mass $m_{H_{2}}$ of $\mathrm{H}_{2}$ in the storage was balanced according to Equation 1.

$$
\frac{d}{d t} m_{H_{2}}=-\frac{1}{\mathrm{LHV}_{\mathrm{H}_{2}}}\left(\eta_{E L Y} P_{E L Y}^{(e l, s e t)}+\frac{P_{F C}^{(e l, s e t)}}{\eta_{F C}}\right)
$$

Here $\eta_{E L Y}=0.51$ and $\eta_{F C}=0.47$ are the efficiencies of ELY and FC. Moreover $P_{E L Y}^{(e l, s e t)}$ and $P_{F C}^{(e l, s e t)}$ are their electric power input values. The model assumes the lower heating value $\mathrm{LHV}_{\mathrm{H}_{2}}$ of $\mathrm{H}_{2}$ as $120 \mathrm{MJ} / \mathrm{kg}$, i.e. $\mathrm{LHV}_{\mathrm{H}_{2}}=33.33$ $\mathrm{kWh} / \mathrm{kg}$. The model was further elaborated to capture time dependent efficiencies, modularity (2 ELYs and 2 FCs), stand by losses of ELY/FC, simple compressor, pressure dependent storage etc.

Model of Liquid Organic Hydrogen Carrier Storage. LOHC is a good alternative to pressurized $\mathrm{H}_{2}$ storages as pointed out before. Demonstration units have been built (e.g. by Hydrogenious (2020) with storing capacity $\dot{m}_{H_{2}}=$ $9.1 \mathrm{~kg} / \mathrm{h}$ and $\dot{m}_{H_{2}}=3 \mathrm{~kg} / \mathrm{h}$ releasing capacity. The maximum parameters of the exemplary households are $0.2 \mathrm{~kg} / \mathrm{h}$ and $0.6 \mathrm{~kg} / \mathrm{h}$ of $\dot{m}_{H_{2}}$ in ELY and FC respectively. Hence, the the size of the demonstration unit would be sufficient for our project.

The previous lumped model of ELY, FC and storage of $\mathrm{H}_{2}$ ( Equation 1), is adapted to capture dehydrogenating specific enthalpy $h^{(d h)}$, needed for extracting $\mathrm{H}_{2}$ out of the LOHC.

$$
\frac{d}{d t} m_{H_{2}}=-\left(\frac{\eta_{E L Y} P_{E L Y}^{(e l, s e t)}}{\mathrm{LHV}_{\mathrm{H}_{2}}}+\frac{1}{\mathrm{LHV}_{\mathrm{H}_{2}}-h^{(d h)}} \frac{P_{F C}^{(e l, s e t)}}{\eta_{F C}}\right)
$$

According to (Krieger 2019) heat up of the liquid (around $300^{\circ} \mathrm{C}$ ) for $\mathrm{H}_{2}$ extraction (dehydrogenation) is realised by burning of $\mathrm{H}_{2}$. A similar amount of heat is released (at slightly lower temperature around $250{ }^{\circ} \mathrm{C}$ ) during the storage of $\mathrm{H}_{2}$ (hydrogenating). Following Hydrogenious (2020), approximately $10 \mathrm{kWh}$ of heat are needed in order to release $1 \mathrm{~kg}$ of $\mathrm{H}_{2}$. Hence, $h^{(d h)}$ was set to $h^{(d h)}=10 \mathrm{kWh} / \mathrm{kg}$. Taking into account $\mathrm{LHV}_{\mathrm{H}_{2}}=33.33 \mathrm{kWh} / \mathrm{kg}$, the overall efficiency of the process, electric power $\rightarrow \mathrm{H}_{2} \rightarrow$ electric power, for LOHC can be evaluated to $\eta_{L O H C}$. It is only 0.165 (Equation 3) compared to 0.25 for pressurized technology
(Equation 4). ${ }^{1}$ The overall efficiency of LOHC (0.165) corresponds to findings in (Krieger 2019). This significantly reduces the attractiveness of LOHC storage, unless the heat produced during hydrogenation is utilized for the dehydrogenation.

$$
\begin{aligned}
\eta_{\mathrm{LOHC}} & =\eta_{\mathrm{ELY}} \cdot \eta_{\mathrm{FC}} \cdot\left(1-\frac{h^{(d h)}}{\mathrm{LHV}_{\mathrm{H}_{2}}}\right) \\
\eta_{\text {Pressurized }} & =\eta_{\mathrm{ELY}} \cdot \eta_{\mathrm{FC}} \cdot \eta_{\mathrm{comp}}
\end{aligned}
$$

This is illustrated in Figure 6. The $\mathrm{LOHC}_{2}$ storage runs empty more than two weeks earlier compared to the pressurised storage. Figure 7 presents a comparison from an el. energy flow perspective. It is evident that LOHC needs to take more electric power from the grid for a longer period of time.

Model of $\mathbf{H}_{2}$ Drying Process. The aim of modelling the $\mathrm{H}_{2}$ drying process was to estimate the energy consumption of that physical process. The model considers the drying of water-vapor saturated $\mathrm{H}_{2}$, which is produced in ELY at 50-70 ${ }^{\circ} \mathrm{C}$, to $200 \mathrm{ppm} \mathrm{H}_{2} \mathrm{O}$ which fulfils the FC-requirement of $500 \mathrm{ppm} \mathrm{H}_{2} \mathrm{O}$ with sufficient margin. The actual ELY available for this project uses a downstream zeolite filled adsorber. The adsorber material has to be exchanged or regenerated (dried out) every 200 hours of operation. This is certainly not acceptable for a continuous long term operation.

Therefore a more useable drying unit based on a condensation/freezing process which is common in practice (Bensmann et al. 2016; Tjarks et al. 2018; Kopp et al. 2017) was modelled in Modelica. The core of the model is a separator (XRG Simulation 2021). It is designed as a pipe that contains a water tank where liquid water is collected. The separator is surrounded by pipes that are filled with cooling liquid. The incoming $\mathrm{H}_{2}$ gas is cooled down in order to decrease its saturation water content until liquid water occurs and freezes. The cooling liquid can also be used to reheat the frozen water.

The $\mathrm{H}_{2}$ drying was added to the energy system model in order to evaluate the electric power consumption of this process. It was observed that electrical consumption of the exemplary households rises due to the drying process of $\mathrm{H}_{2}$ just by $70 \mathrm{kWh} /$ year $\left(\sim 0.2 \mathrm{kWh} / \mathrm{kg} \mathrm{H} \mathrm{H}_{2}\right)$, which is $\sim 0.5 \%$ of the overall generated $L H V_{H 2}$ or $\sim 0.2 \%$ of total consumed el. power/year.

System Models. The overall model of the system has been developed at different levels of complexity. Firstly, a simple model with no logic has been created in Modelica, entirely from TransiEnt library components.

It uses all boundary conditions given from the linear optimisation results (such as electricity production from PV, electricity demand of households, electricity flow to/from batteries, electricity production from $\mathrm{FC}$ and electricity demand by ELY). Only the electricity flow from/to

\footnotetext{
${ }^{1}$ Efficiency of the considered compression work $\eta_{\text {comp }}$ in the overall energy system is close to 1 .
} 
the grid is let free to be calculated. The boundary conditions are specified by hourly based time tables supplied by a text file. The model is connected to a lumped grid model, including primary and secondary control models. It includes a lumped generator model to mimic the synchronous grid of Continental Europe (UCTE).

In the final system model, (see Figure 1), fixed boundary conditions for usage of ELY/FC and batteries were replaced by physical models and corresponding control logic. The system model plus the control logic were kept the same for all storage technologies.

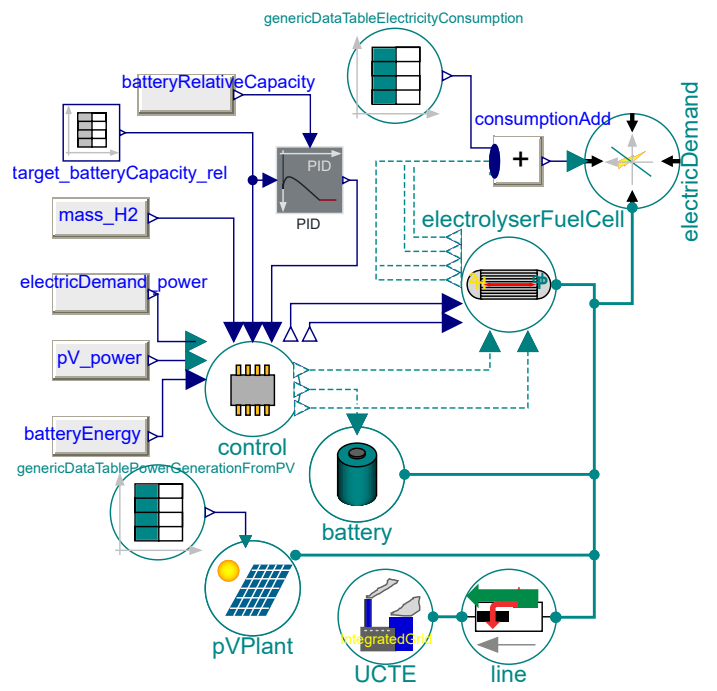

Figure 1. Final model of the energy system of households with control logic.

Resulting Objectives. Using the described inputs and models, the goal is to perform a technical and economic evaluation of pressurized and $\mathrm{LOHC}$ based $\mathrm{H}_{2}$ storage technologies for three different $\mathrm{H}_{2}$ storage capacities $\{200,300,400\} \mathrm{kg}$ for 30 years of operation. In particular we have to tackle the following tasks:

1. Re-examine the results of linear optimisation: are they consistent with the physical model?

2. Develop a control logic of the energy system storage in order to answer e.g.

(a) Shall excess power produced from photovoltaic (PV) be firstly stored in batteries (if they have capacity available) or shall it be used to fill up $\mathrm{H}_{2}$ storage?

(b) If the two modules of ELY/FC shall operate, can/shall battery in some scenario supply power to ELY to charge $\mathrm{H}_{2}$ storage?

3. Capture physical constraints (physicalities)

(a) ELY/FC: startup time (heat up and lower efficiency), efficiency, power consumption during standby mode, two separate modules, each with minimum operation power

(b) compressor for pressurised bottle storage (c) pressure dependent storage capacity

(d) power consumption of hydrogen drying process (condensation/freezing)

4. Add weather and consumption forecast model into control logic.

5. Incorporate a cost model for all $\mathrm{H}_{2}$ system components in order to predict the costs over 30 years.

\subsection{Creating a Detailed Control Logic}

In the sequel, we describe the emergence of the control logic as a step by step iteration benchmarked by the linear optimisation result. The initial simple Modelica model is further enhanced towards a more sophisticated logic and the previously described objectives.

\subsubsection{Re-examination of Linear Optimisation Result}

Figure 2 gives a comparison of the resulted energy flow to/from grid ${ }^{2}$ by the simple system model of paragraph 2.3 and the linear optimisation model (see subsection 2.1) for a one year evaluation. There is a clear agreement of the results. Although, a slight deviation (max. $6 \%$ ) can be observed, which is caused by hourly sampling of the linear optimsation: The values assumed constant by linear optimisation are not necessarily constant throughout 1 hour in the dynamic model.

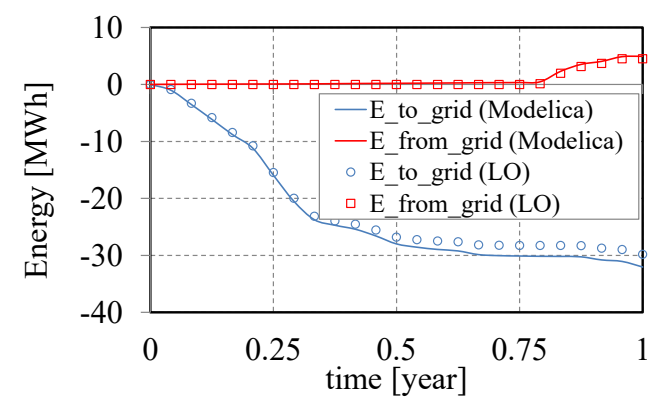

Figure 2. Comparison of el. energy flow results from a Modelica and linear optimisation model with no logic for $200 \mathrm{~kg} \mathrm{H}_{2}$ storage.

Simulation starts in the beginning of March which brings more sunny days and the PV power exceeds the household consumption together with battery and ELY capacity. This results in a continuous rise of Energy put to the exterior electric grid until October ( $\frac{2}{3}$ of the year). The Energy taken from the grid starts to dominate from around November ( $\frac{3}{4}$ of the year) as soon as the $\mathrm{H}_{2}$ storage is emptied and the power of $\mathrm{PV}$ is almost zero.

\subsubsection{Model with Simple Logic}

A next step was the development of a very first simple logic for distribution of energy flows between grid, batter-

\footnotetext{
${ }^{2}$ Energy from a grid has a positive sign and Energy to a grid has a negative sign.
} 
ies, ELY and FC. The logic ${ }^{3}$ is depicted in Figure 3.

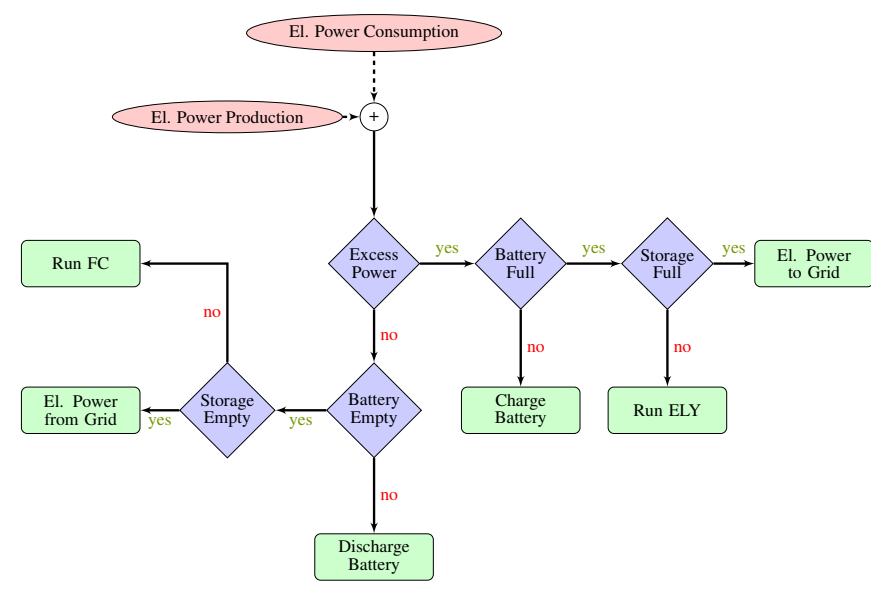

Figure 3. First simple control logic.

This logic is plugged into the simple overall energy system model (paragraph 2.3) and replaces fixed boundary conditions of battery, ELY and FC by realistic components, as shown in Figure 1. Hence, it uses electricity production from PV and electricity demand of households as table based bounday condition and the rest is calculated, i.e. electricity flow to/from batteries, electricity production from FC and electricity demand by ELY, electricity flow to/from grid). The simple logic model further assumes 1 lumped battery module, 1 lumped FC module and 1 lumped ELY module.

Figure 4 reveals the limitations of the simple logic. Maximum mass of $\mathrm{H}_{2}$ in storage that is possible to reach with this simple logic is only $230 \mathrm{~kg}$, while the results from linear optimisation show $400 \mathrm{~kg}$. It reveals much lower $\mathrm{H}_{2}$ production (of Modelica simulation) which results in a clear lack of $\mathrm{H}_{2}$ in the storage already in the beginning of December ( $\left(\frac{5}{6}\right.$ of the year). Clearly this is caused by the fairly immature control logic applied for initial implementation. Hence, further enhancement of the control logic was required.

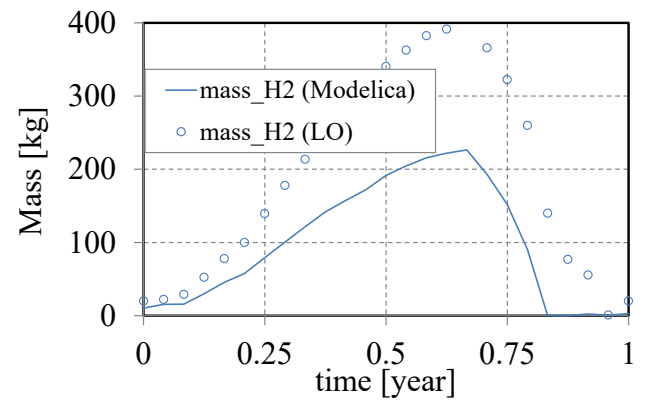

Figure 4. Comparison of resulted mass of $\mathrm{H}_{2}$ in storage from a Modelica and linear optimisation model with simple logic.

It was found that the capacity of the battery stays most of the time in its upper range and frequently reaches its

\footnotetext{
${ }^{3}$ If max. power of the components is reached then the excess power is taken or send to the grid.
}

maximum and thus limits its further usage. This is different from the linear optimisation result and indicates an important direction for improvement.

\subsubsection{Model with Improved Logic}

Based on the previous unsatisfactory behaviour of the energy distribution in the system, an improved logic was worked out, see Figure 5. It was based on the simple logic and several extra features were added.

The first enhancement. The battery usage is optimised such that if battery is able to unload, i.e. has capacity, it shall distribute its power between household consumption demand and ELY. This is controlled according to a PID controller, see Figure 1. The PID controls the capacity level of the battery based on a Forecast model which computes target charge capacity for batteries. The principle of the Forecast model is as follows: The model looks 24 hours ahead for a predicted power consumption $P_{c o n}(t)$ of households and assumed power production from PV $P_{P V}(t)$. The integrated sum for upcoming 24 hours of the two above-named powers gives the required needed capacity for the batteries $E_{\text {store }}$ as given in Equation 5 . The relative $E_{\text {storeRel }}$ is defined as in Equation 6 where $E_{\text {batteryNom }}$ is the nominal battery capacity (e.g. maximum battery capacity). Then one can derive the relative target capacity of battery $E_{\text {batteryTarget }}$ according to Equation 7 using limited $E_{\text {storeRel }}$. The $E_{\text {batteryTarget }}$ is then kept constant for each upcoming 24 hours. In the simulations, the minimum value of $E_{\text {batteryTarget }}$ was set to 0.35 in order to have some margin for electricity demand needs. Otherwise, electricity from the grid would be frequently unintentionally used. Finally, the control logic contains a PID controller that keeps relative battery storage $E_{\text {batteryRel }}$ close to the value of $E_{\text {batteryTarget }}$ by using the free capacity of battery to charge ELY. The $E_{\text {batteryRel }}$ is prescribed as in Equation 8.

$$
\begin{aligned}
& E_{\text {store }}=\int_{t_{0}}^{t_{0}+24 h}\left(P_{\text {con }}(t)+P_{P V}(t)\right) d t \\
& E_{\text {storeRel }}=\frac{E_{\text {store }}}{E_{\text {batteryNom }}} \\
& E_{\text {batteryTarget }}=1-\min \left(1, \max \left(0, E_{\text {storeRel }}\right)\right) \\
& E_{\text {batteryeRel }}=\frac{E_{\text {battery }}}{E_{\text {batteryNom }}}
\end{aligned}
$$

The second enhancement. The logic is enabled to simultaneously run ELY and charge batteries if there is enough excess power.

The key set of rules for the improved control logic can be summarized as follows:

\section{- Charging of battery:}

Battery is charged if there is excess of power while battery is not yet full. The charging power is derived as excess power minus the power taken by ELY. 


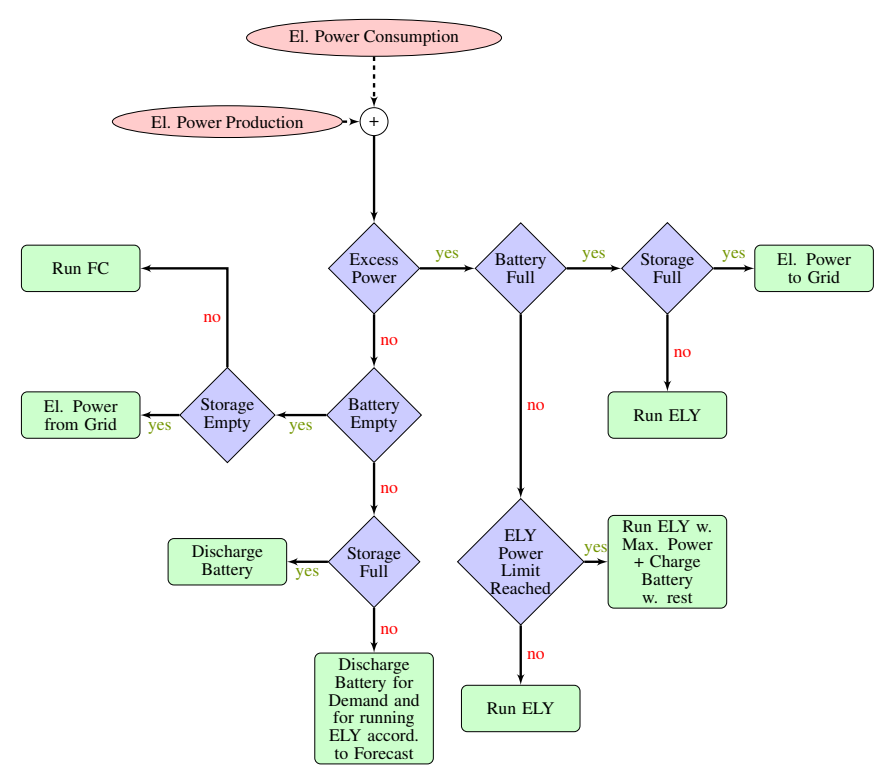

Figure 5. Advanced control logic.

\section{- Discharging of battery:}

Battery is discharged for a load demand or for the ELY if there is a load demand and battery and $\mathrm{H}_{2}$ storage is not full.

\section{- FC usage:}

FC is used if there is a load demand and battery is empty and $\mathrm{H}_{2}$ storage is not empty.

- ELY usage:

ELY is used if there is excess power and battery is full and storage is not full. Further, use ELY if there is excess power to simultaneously charge ELY and battery and if there is enough power to charge both ELY and battery (otherwise only ELY, i.e. ELY has priority). Finally, use ELY from battery power, but only if there is net demand for power in the system (otherwise undesired charging of battery with simultaneous discharging of battery for ELY would appear). It would go against each other.

Resulting system operation. Finally, with this improved logic, a maximum of $400 \mathrm{~kg}$ of $\mathrm{H}_{2}$ can be reached as presented in the Figure 6 (curve labelled as ideal) which is in agreement with the linear optimisation analysis. Subsequently, the battery usage is enhanced. However, what the Figure 6 additionally shows is that when further physical constraints (subsection 2.4), to mimic realistic behaviour of the system, is implemented, $\mathrm{H}_{2}$ mass reduces dramatically. For example, the maximum of $\mathrm{H}_{2}$ mass in storage barely reaches $340 \mathrm{~kg}$, i.e. just $85 \%$ of the idealized scenario. The LOHC process only reaches $300 \mathrm{~kg}$, due to the worse efficiency of the process. In Table 3, the main results are shown for $400 \mathrm{~kg}$ pressurized $\mathrm{H}_{2}$ storage for ideal (no physicalities) and real (with physicalities) case.

Note that ELY and FC units each consist of two independent modules (two numbers in brackets in Table 3 ) and

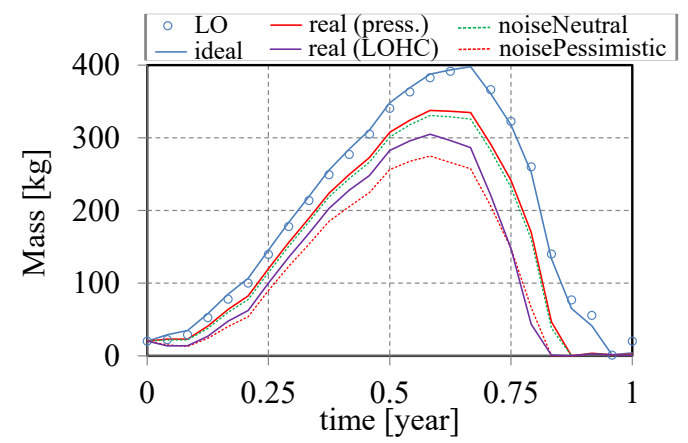

Figure 6. Comparison of resulted mass of $\mathrm{H}_{2}$ in storage from Modelica and linear optimisation (LO) model with improved logic for ideal (no physicalities) and real (with physicalities described in subsection 2.4) pressurised+LOHC case together with real pressurised case with neutral and pessimistic noise.

Table 3. Overview of results for pressurized $400 \mathrm{~kg} \mathrm{H}_{2}$ storage for ideal (no physicalities) and real (with physicalities) case.

\begin{tabular}{|c|c|c|}
\hline Quantity & Value $_{\text {ideal }}$ & Value $_{\text {real }}$ \\
\hline El.power ${ }_{\text {from Grid }}$ & $1.6 \mathrm{MWh}$ & $3.8 \mathrm{MWh}$ \\
\hline El.power $_{t o G r i d}$ & $17.3 \mathrm{MWh}$ & 16.7 MWh \\
\hline Start/Stop ELY & $\{256 / 256\} / a$ & $\{278 / 277\} / \mathrm{a}$ \\
\hline Start/Stop FC & $\{136 / 136\} / \mathrm{a}$ & $\{223 / 223\} / \mathrm{a}$ \\
\hline Runtime ELY & $\{3043 / 3040\} \mathrm{h} / \mathrm{a}$ & $\{2814 / 2813\} \mathrm{h} / \mathrm{a}$ \\
\hline Runtime FC & $\{1603 / 1585\} \mathrm{h} / \mathrm{a}$ & $\{1332 / 1330\} \mathrm{h} / \mathrm{a}$ \\
\hline
\end{tabular}

for the case with physicalities, the minimum power limitation of one unit causes more start/stop cycles. However, it remains well below the limits.

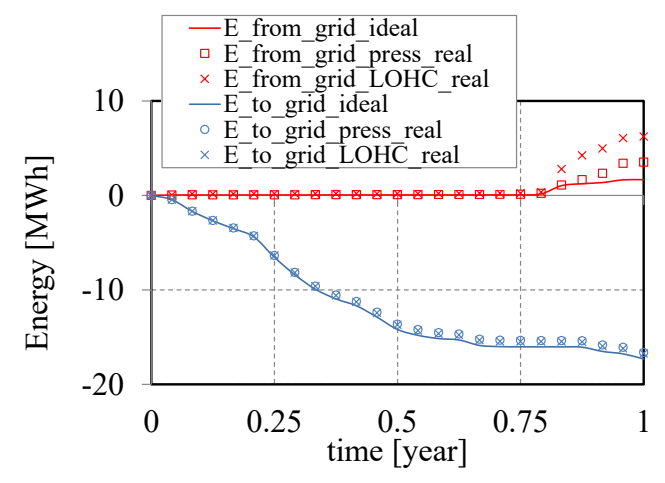

Figure 7. Comparison of el. energy flow results of a ideal pressurized $400 \mathrm{~kg} \mathrm{H}_{2}$ case (no physicalities) together with pressurized real and LOHC technology (with physicalities).

Figure 6 further demonstrates the functionality of the logic in case of forecast errors: Random noise is added to the original boundary condition of the real case. The noisePesimistic case introduces random noise to power consumption with range $(0 \%$ to $+20 \%$ of original) and noise to PV production ( $0 \%$ to $-20 \%$ of original values). Similarly in the noiseNeutral case the range was chosen for power consumption and PV production $( \pm 20 \%$ of original values). 
Variation of geographic location Our system model was further extended to consider different geographic locations. The reference site was Jena (Germany) and we chose one northern and one southern European city, i.e. Copenhagen (Denmark) and Marseille (France) respectively. A model from HumanComfort Modelica library HumanComfort v.2.11 (2020) was used in order to calculate the sun position dependent on the location and solar time. Together with the maximal possible solar irradiance $\left(1367 \mathrm{~W} / \mathrm{m}^{2}\right)$ the Extraterrestrial irradiance on horizontal earth's surface $\left(\mathrm{G}_{\text {extHor }}\right)$ is calculated for each location for the whole one year period. The value of $\mathrm{G}_{\text {extHorRef }}$ for Jena was used as a base and the scaling factors for the two other locations ( $\mathrm{r}_{\text {Copenhagen }}$ for Copenhagen) were derived as a ratio of the day integrals of the corresponding $\mathrm{G}_{\text {ext } H o r}$ values as follows:

$$
r_{\text {Copenhagen }}(t)=\frac{\int_{t}^{t+24 h} G_{\text {extHorCopenhagen }}(\tau) d \tau}{\int_{t}^{t+24 h} G_{\text {extHorRef }}(\tau) d \tau}
$$

and $\mathbf{r}_{\text {Marseille }}$ for Marseille was derived in similar manner. Using these ratios the reference electricity PV production for Jena was scaled for the other locations. Finally, $E_{\text {batteryTarget }}$ (Equation 7) was recalculated (for Copenhagen and Marseille) and used in the improved control logic. Certainly this is a simplified approach (the same weather data is assumed since we don't have weather data for reference site, fixed PV efficiency, horizontal PV, same consumption power (heating), neglect different sunrise/sunset time). But it demonstrates the universality of the system model and can be improved without much effort. The resulting simulations indicate e.g. that the maximum of $\mathrm{H}_{2}$ mass in storage barely reaches $310 \mathrm{~kg}$ (9\% reduction) for Copenhagen, while for Marseille the maximum of $\mathrm{H}_{2}$ mass reaches $366 \mathrm{~kg}$ (8\% increase). Further comparisons are displayed in Table 4.

\section{Evaluation of results}

\subsection{Level of autarky}

One of the key performance indicators for effectiveness of $\mathrm{H}_{2}$ storages is the Level of autarky (LoA), indicating how self-sufficient the system is. We consider two levels of autarky here. One, in terms of energy taken from the grid $L o A_{\text {energy, }}$, and the other with regard to time span of energy taken from the grid $L o A_{\text {time }}{ }^{4}$

$$
\begin{aligned}
L o A_{\text {energy }} & =1-\frac{\int_{0}^{1 \text { year }}\left(P_{\text {con }}(t)-P_{\text {prod }}(t)\right) \sigma(t) d t}{\int_{0}^{1 \text { year }} P_{\text {con }}(t) d t} \\
L o A_{\text {time }} & =1-\frac{\int_{0}^{1 \text { year }} \sigma(t) d t}{\int_{0}^{1 \text { year }} t d t}
\end{aligned}
$$

Here a time dependent characteristic function $\sigma(t)$ is introduced:

$$
\sigma(t)= \begin{cases}1 & \text { if power taken from grid } \\ 0 & \text { else }\end{cases}
$$

\footnotetext{
${ }^{4}$ Overproduced energy sent to the grid was not counted.
}

$P_{\text {prod }}$ is the power actual provided by the internal system (PV, battery, FC) and $P_{\text {con }}$ is the actual power demand. If $P_{\text {prod }}<P_{\text {con }}$ then the difference results in power taken from the grid. Comparison of different variants of $\mathrm{H}_{2}$ storages with regard to level of autarky is summarized in Table 4 .

Table 4. Comparison of different variants of $\mathrm{H}_{2}$ storages with regard to level of autarky.

\begin{tabular}{lll}
\hline $\begin{array}{l}\text { Type of } \mathrm{H} 2 \text { storage/capacity } \\
\text { of storage }[\mathrm{kg}]\end{array}$ & LoA energy & LoA time \\
\hline Pressurized/400 (real) & 0.91 & 0.93 \\
Pressurized/300 (real) & 0.89 & 0.91 \\
Pressurized/200 (real) & 0.87 & 0.89 \\
LOHC/400 (real) & 0.84 & 0.88 \\
Pressurized/400 (ideal) & 0.96 & 0.96 \\
Pressurized/300 (ideal) & 0.92 & 0.93 \\
Pressurized/200 (ideal) & 0.88 & 0.91 \\
No storage (batteries only) & 0.79 & 0.84 \\
Pressurized/400 (realCopenhagen) & 0.87 & 0.89 \\
Pressurized/400 (realMarseille) & 0.96 & 0.97 \\
\hline
\end{tabular}

The results of ideal simulations, i.e. without physicalities show good agreement with the linear optimisation analysis (Table 2). However, one can see how the level of autarky drops when real behaviour of components is considered. The variant with $400 \mathrm{~kg}$ pressurized storage has the highest autarky level considering physicalities $\left(L o A_{\text {energy }}=0.91\right.$ and $\left.L o A_{\text {time }}=0.93\right)$. Here the complex of households would take from the electric grid $\sim 3.4 \mathrm{MWh} /$ year (out of total consumed el. power 37.5 $\mathrm{MWh} /$ year) and it would need to take electric power from the grid for $\sim 25$ days out of the whole year. The worst combination regarding $L o A$ is the $\mathrm{LOHC}$ variant due to the poor efficiency of the LOHC process $\left(L o A_{\text {energy }}=0.84\right.$ and $L o A_{\text {time }}=0.88$ ). This variant would increase both $L o A_{\text {energy }}$ and LoA time by just $4 \%$ as compared to a system with batteries only, without $\mathrm{H}_{2}$ storage. As one would intuitively expect, the difference in $L o A$ is mainly driven by the time it takes until the $\mathrm{H}_{2}$ storage is empty in autumn (Figure 6).

\subsection{Cost Model}

Together with the technical analysis, an economical analysis for 30 years of operation was performed as well. For this, a one year simulation is extrapolated to 30 years of operation by simple duplication. We are aware that this neglects possible future developments, fostering energy autarkic settlements. These are for example: increasing electricity price over time, additional profit from $\mathrm{CO}_{2}$ certificate trade, control energy offer and negative electricity prices. Moreover governmental subsidiary programs for storage technologies as well as improved efficiency of FC/ELY and lower component prices. The simplified cost extrapolation can be seen as a conservative point of view: any of the mentioned future energy market and technol- 
ogy improvements will lower our cost prognosis in favour of a storage technology. Determination of costs for the different $\mathrm{H}_{2}$ storage variants was accomplished with help of the so called collectCosts models implemented in the TransiEnt Modelica library. They were included in the hydrogen system components and cover investment, operational and maintenance, demand (e.g. purchasing of el. energy), revenues (e.g. selling el. energy) and other costs. The economical analysis was performed under the following assumptions:

- Only hydrogen system components costs were considered (PV and batteries were the same for each variant so it was omitted). ${ }^{5}$ (Table 5)

- Price of occupied land was included for storages only $\left(300 € / \mathrm{m}^{2}\right)$. (Table 5)

- Energy costs were included:

Demand (from grid) as $0.3 € / \mathrm{kWh}$

Revenue (to grid) as $0.1 € / \mathrm{kWh}$

- Lifetime of components was covered.

ELY/FC : 10 years

Bottles / Tank / Compressor: 20 years

LOHC storage: 20 years

- Annuity factor for 30 years set for $1 / 30$ (i.e. numerical zero interest rate).

- No operational and maintenance cost were assumed but is adaptable in the model ${ }^{67}$

Table 5. Costs for hydrogen related components.

\begin{tabular}{ll}
\hline Components & Cost $[\mathrm{k} €]$ \\
\hline ELY $(2 \times 5.8 \mathrm{~kW}$ units $)$ & 60 \\
$\mathrm{FC}(2 \times 4.7 \mathrm{~kW}$ units $)$ & 130 \\
Bottles $(\{200 / 300 / 400\} \mathrm{kg})$ & $90 / 130 / 170$ \\
additional land cost & $8 / 12 / 16$ \\
Tank $(\{200 / 300 / 400\} \mathrm{kg})$ & $220 / 360 / 440$ \\
additional land cost & $17 / 26 / 34$ \\
Compressor & 70 \\
LOHC storage $(\{200 / 300 / 400\} \mathrm{kg})$ & $390 / 430 / 470$ \\
additional land cost & $-/ / 8$ \\
\hline
\end{tabular}

The final comparison of different variants of $\mathrm{H}_{2}$ storages (type and capacity $\{400,300,200\} \mathrm{kg}$ ) with regard to costs for 30 years of operation is summarized in Table 6. As expected, the cheapest variant for a $\mathrm{H}_{2}$ storage is 200 $\mathrm{kg}$ with bottles. However, the $400 \mathrm{~kg}$ storage using bottles is "just" $150 \mathrm{k} €$ more expensive and offers much more

\footnotetext{
${ }^{5}$ Component cost data sourced: LOHC (Hydrogenious 2020), pressurized bottles (BBA 2017), pressurized tank (ELKUCH 2019).

${ }^{6}$ in (Gstöhl and Pfenninger 2020) $7.5 \%$ of initial investment sum is assumed.

${ }^{7}$ The last two assumptions might seem too primitive. However there are other uncertainties, such as constant electricity price etc., which have larger impact on the costs. In the scope of this work it is sufficient for comparison of the technologies.
}

Table 6. Comparison of different variants of $\mathrm{H}_{2}$ storages with regard to costs in $\mathrm{k} €$ for 30 years of operation.

\begin{tabular}{lllll}
\hline Storage/capacity & Invest. & Reven. & Deman. & Total \\
\hline Bottles/400 & 956 & 50 & 34 & 941 \\
Bottles/300 & 879 & 60 & 39 & 858 \\
Bottles/200 & 813 & 81 & 55 & 786 \\
Tanks/400 & 1365 & 50 & 34 & 1349 \\
Tanks/300 & 1136 & 60 & 39 & 1115 \\
Tanks/200 & 919 & 81 & 55 & 893 \\
LOHC/400 & 1307 & 50 & 56 & 1313 \\
No storage & 0 & 147 & 72 & -75 \\
\hline
\end{tabular}

flexibility, hence much higher level of autarky. The 400 $\mathrm{kg}$ storage using tanks is the most expensive variant $(\sim 1.5$ times more than $400 \mathrm{~kg}$ bottle storage) even more expensive than the LOHC. At the moment the HB system is not economically competitive in comparison to standard energy supply. These findings are supported by Grosspietsch et al. (2018).

\section{Summary \& Outlook}

From today's perspective, applying a $\mathrm{H}_{2}$ storage does not pay off economically. This points towards a necessity for adjusting political/economical conditions as well as a need for technical improvements, see subsection 3.2. As for today, pressurized and $\mathrm{LOHC}$ storages of $\mathrm{H}_{2}$ are the favourite choices in terms of technical readiness, safety and economy. Based on our results, a storage consisting of pressurized gas bottles gives the most economic solution. If the LOHC technology becomes more affordable in the future and most importantly its efficiency becomes higher or if there exists a possibility to recuperate the heat produced during hydrogenation then LOHC might become a real option. Safety is a pro of LOHC, since $\mathrm{H}_{2}$ is stored under ambient condition and in a hardly inflammable state.

The developed system model including control logic is quite universal: without much modelling effort, it can be extended by other energy producers, e.g. by wind turbines and a wind forecast, while keeping the control logic model untouched. Also maintenance costs and annuities can be included. Hence, the energy system can be customized to specific technological set ups. Also the geographic location of the house complex can be varied by providing weather and modified (merely) heat consumption data. This enables location dependent design studies for residential complexes. Further, our model can be used for an optimised system design based on physicalities also regarding storage tank and battery capacity.

Our work demonstrates how a linear optimisation can guide the development of a more detailed physical Modelica model of the storage system. Simultaneously it points out the necessity of dynamic simulations in the design process of the storage: The effects of control decisions and 
physicalities integrated over the investigated operational time period of 1 year have a substantial impact on the level of autarky (e.g. $96 \% \rightarrow 91 \%$ wrt. total energy consumption) and maximum mass ( $\sim 15 \%$ decrease $)$ of stored hydrogen.

Modelica has proved to be an adequate numerical tool to tackle these kinds of analyses. Using a combination of TransiEnt and ClaRa library as well as e.g. XRG's HumanComfort and HVAC library opens the door for detailed system models of residential house complexes, including the buildings and their heating systems.

\section{Acknowledgements}

This work has been supported by the German Federal Ministry for Economic Affairs and Energy within the scope of the $6^{\text {th }}$ energy research program (grant number 03ET6059A).

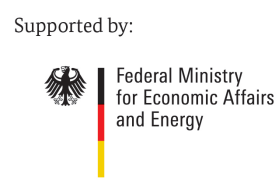

on the basis of a decision by the German Bundestag The authors thank the anonymous referees for valuable comments and suggestions.

\section{References}

BBA (2017). Ed. by BBA Müller GmbH. fetched Apr., 6th 2021. URL: https://www. messe- essen-digitalmedia.de/uploads/ E301/pdf/company/bba-mueller-gmbh-e2f6e-info.pdf.

Bensmann, B. et al. (2016). "Optimal configuration and pressure levels of electrolyzer plants in context of power-to-gas applications". In: Applied Energy 167.1-2, pp. 107-124.

Bentvelsen, R. F. P. (2019). "Modeling and Scheduling of a ControllableElectrolyser in an IndustrialGrid". MA thesis. Delft University of Technology, Netherlands.

BMU, ed. (2011). Berlin. URL: http : / / www . verwaltungsvorschriften - im - internet . de / bsvwvbund 13122011_KIIII54603022.htm (visited on 2021-04-11).

BMU (2021). Gesetz für den Ausbau erneuerbarer Energien (Erneuerbare-Energien-Gesetz - EEG 2021). German. Ed. by German Federal Ministry of Justice and Consumer Protection and German Federal Office of Justice.

ClaRa v1.3.0 (2020). Ed. by ClaRa Development Team. fetched Apr., 6th 2021. URL: https://claralib.com/.

ELKUCH (2019). Ed. by LUDWIG ELKUCH AG. fetched Apr., 6th 2021. URL: https://www.elkuch.com.

Frey, Hartmut (2019). Energieautarke Gebäude: Auf dem Weg zu Smart Energy Systems. 1. Auflage 2019. Berlin, Heidelberg: Springer Berlin Heidelberg. ISBN: 3662578743.

Fritzson, Arash M.; Dizqah Alireza Maheri; Krishna Busawon; Peter (2013). "Modeling and Simulation of a Combined Solar and Wind Systems using OpenModelica". In: Annual OpenModelica Workshop, LinkÃIlping University,Sweden.

FuelCellStore (2020). Ed. by Fuel Cell Store. fetched Apr., 6th 2021. URL: https://www.fuelcellstore.com.

Grosspietsch, David et al. (2018). "How, When, and Where? Assessing Renewable Energy Self-Sufficiency at the Neighborhood Level". In: Environmental science \& technology 52.4, pp. 2339-2348. DOI: 10.1021/acs.est.7b02686.

Gstöhl, Ursin and Stefan Pfenninger (2020). "Energy selfsufficient households with photovoltaics and electric vehicles are feasible in temperate climate". In: PloS one 15.3, $\mathrm{e} 0227368$.
Henriquez, A. M. (2018-06-08). "Model of hydrogen production system for investigating the energy flexibility of residential buildings". MA thesis. UNIVERSITY OF LIEGE BELGIUM, p. 76.

Hilpert, S. et al. (2018). "The Open Energy Modelling Framework (oemof) - A new approach to facilitate open science in energy system modelling”. In: Energy Strategy Reviews 22, pp. 16-25.

HPS Home Power Solutions GmbH, ed. (2021). HPS System picea. URL: https://www. homepowersolutions . de/produkt (visited on 2021-07-05).

HumanComfort v.2.11 (2020). Ed. by XRG Simulation. fetched Apr., 6th 2021. URL: https ://www.xrg-simulation.de/en/ products/xrg-library/humancomfort/.

HydrogenEurope (2020). Ed. by Hydrogen Europe AISBL. fetched Apr., 6th 2021. URL: https://www.hydrogeneurope. $\mathrm{eu} /$.

Hydrogenious (2020). Ed. by Hydrogenious LOHC Technologies GmbH. fetched Apr., 6th 2021. URL: http://www.hystoc. $\mathrm{eu} /$.

Kofman, G. Migoni; P. Rullo; F. Bergero; E. (2016). "Efficient Simulation of Hybrid Renewable EnergySystems". In: International Journal of Hydrogen Energy 41.32.

Kopp, M. et al. (2017). "Energiepark Mainz: Technical and economic analysis of the worldwide largest Power-to-Gas plant with PEM electrolysis". In: International Journal of Hydrogen Energy 42.19, pp. 13311-13320.

Krieger, Christoph (2019). "Process engineering consideration and optimization of the release of hydrogen from organic carrier materials (LOHC)". Doctoral dissertation. FriedrichAlexander-Universität Erlangen-Nürnberg (FAU), p. 121.

Macagno, M. Santarelli; S. (2004). "A thermoeconomic analysis of a PV-hydrogen system feeding the energy requests of a residential building in an isolated valley of the Alps". In: Energy Conversion and Management 45 (3), pp. 427-451.

PHI (2021). Passive House Institute (PHI) website. URL: https: //passivehouse.com/ (visited on 2021-04-13).

Proton Motor Fuel Cell GmbH (2021). PEM-fuel cell. URL: https://www.proton-motor.de/en/ (visited on 2021-04-21).

ResiliEnt.EE (2021). - Resilience of integrated energy networks with a high share of renewable energies. URL: https://www. tuhh.de/transient-ee/en/index.html.

Scarisbrick, Constantin (2019). "Simulation of a Fuel Cell and a Metal Hydride Storage System". Diploma Thesis. Technical University of Vienna, Austria. 73 pp.

Stiftung Umwelt Arena Schweiz, ed. (2021). Umweltarena Brütten. URL: http://www.umweltarena.ch/ (visited on 2021-0705).

Tjarks, Geert et al. (2018). "Energetically-optimal PEM electrolyzer pressure in power-to-gas plants". In: Applied Energy 218.12, pp. 192-198.

TransiEnt v1.2.0 (2020). Ed. by TransiEnt Development Team. fetched Apr., 6th 2021. URL: https://www.tuhh.de/transientee/index.html.

University of Wisconsin-Madison Solar Energy Laboratory (1975). TRNSYS, a transient simulation program. Madison, Wis. : The Laboratory, 1975.

Vezzoli, Carlo (2018). Designing sustainable energy for all: Sustainable product-service system design applied to distributed renewable energy. Green energy and technology. Cham, Switzerland: Springer.

XRG Simulation (2021). "in-house Modelica library for FuelCells and Electrolysers". 